\title{
Introduction to Part IV
}

\section{Thom Davies}

Data is discard: in an uneven world of cloud-sourced devices, we are rendered data factories, spilling our information in real time to anyone who might be listening. Everything we tweet, "like," or Google has become a marketized product to be salvaged, mined, and rendered capital. Never before has the volume and velocity of data been so available and so open to manipulation. Some have argued that data has replaced oil as the world's most valuable commodity (The Economist 2017): a resource that can pollute politics and link power and big business in unforeseen ways. While it might be wrong to imagine "a prelapsarian past in which truth legitimately preceded and guided politics" (Jasanoff and Simmet 2017, 753), today, the rise of "big data" has opened up new avenues for "post-truth" to thrive, with potential environmental consequences. The success of populist movements such as Trump and Brexit, as well as political campaigns in Kenya and Nigeria, have all been linked to the data analytics of political consulting firms such as Cambridge Analytica (Persily 2017); future elections, it seems, may be won and lost by the crunch of code.

If data is the new oil, when it comes to actual pollution, data also plays a vital role. The pollution data produced by multinational companies and environmental regulators is often at odds with the lived experience of frontline communities. In response, environmental justice activists have often attempted to record their own data about toxic hazards using a gamut of citizen science techniques. This is especially important considering that the burden of proof of 
environmental damage often falls on affected communities, as opposed to the polluters themselves (Mah 2017). In an age of post-truth and alternative facts, questions of data, proof, and even citizenship have become especially acute. How can people who live with toxic injustice create their own facts about pollution? How can non-scientists make their alternative data count in environmental disputes? Can citizen science be expanded to include people whose citizenship is disputed? Can the practices of citizen science ever create environmental justice, if injustice is built on a bedrock of political inequality? These are some of the questions explored by the authors in the final section of Toxic Truths.

Citizen science refers to research that is performed by, and in the interests of, citizens. In the context of environmental justice, citizen science means adopting technoscientific practices by the public themselves to measure, assess, and sometimes protest their concerns about the environment. Though citizen science may sometimes ape formal science - ventriloquizing its symbolic capital - it also offers a form of public fact-making that is unencumbered by the burden of official training. It allows frontline communities to tell their own non-hegemonic "guerilla narratives" (Armiero et al. 2019) about the toxicants that they live and breathe with. Often it involves simple, low-cost, open-source devices, sensors, and strategies that enable ordinary people to make sense of toxic pollution, and advocate for a healthier environment. As we discussed in the introduction to this book, citizen science covers a wide range of practices and techniques which involve varying levels of participation by non-professionals. Though scholarship on citizen science took hold from the end of the last century (Irwin 1995; Bonney 1996), it built upon the legacies of amateur naturalists in the nineteenth century and radical scientists in the 1960s (Strasser et al. 2019). Today, this amateur and radical legacy pulls citizen science in different directions, as evidenced in the wide range of citizen science performed today. It can include the relatively passive crowdsourcing of information from the public - where citizens become little more than data points or "sensing nodes" (Gabrys 2014, 32) - to deeply participatory research, where community members themselves lead the planning, production, and analysis of environmental research (see Allen, this volume). Citizen science has particular relevance as we navigate an era of posttruth, which "emphasizes the weakness of factual, science-based explanations in the face of strong narratives or a compelling story" (Berling and Bueger 2017, 332). Citizen science challenges this supposed dichotomy between fact and narrative, allowing local communities to tell their own stories about pollution using publicly generated science.

Noise, ozone, oil, chemical, nuclear, water, and air pollution have all been monitored through citizen science campaigns, with cheap particle sensors, DIY devices, and open-source hardware allowing volunteers to provide new nar- 
ratives about environmental injustice, using their own data. Famous examples of citizen science include the Louisiana Bucket Brigade, who used simple "bucket samples" of polluted air as part of grassroots environmental justice campaigns against the toxic racism of petrochemical companies (see Ottinger 2010). Citizen science has also been deployed in the wake of disasters such as the 2010 BP oil spill in the Gulf of Mexico - the largest maritime industrial accident the world has ever seen - where Public Lab deployed kite-flown cameras to witness the extent of crude oil pollution on the vulnerable wetlands of the Gulf coast (Breen et al. 2015); or the 2011 nuclear disaster in Fukushima, Japan, where Safecast provided cheap Geiger counters, and self-assembly monitors, to help concerned Japanese citizens measure the levels of harmful radiation in and around their homes, creating reliable crowdsourced radiation maps (Brown et al. 2016).

The link between citizen science and environmental justice is not always a smooth process, however. Some scholarship has started to question whether public participation and citizen science necessarily leads to environmental justice at all (Topçu 2013). Some citizen science schemes have been actively reluctant to take sides in environmental controversies, and have instead adopted for an outwardly neutral " "pro data' policy” (see Brown et al. 2016, 93). In some cases, citizen science can produce cases of "conflictual collaboration" (Polleri 2019 , 214) where publicly generated data becomes co-opted by state actors to reinforce hegemonic governance of toxic risks. In the USA, for example, several US departments, including the Environmental Protection Agency, have adopted the language of citizen science, promoting an "Air Sensor Toolbox" as means to tackle air pollution (Bonney et al. 2016).

There is a danger of citizen science being uncritical of wider political structures, where a frictionless pathway is imagined between citizen science data and environmental justice: according to this fiction, the "right facts" will create the right political ecology. In this sense, citizen science not only emulates some of the practices of formal science, but also some of its ontological shortcomings. To put it another way, in order for citizen science to produce environmental justice, it "will require joining the epistemological with the political" (Strasser et al. 2019, 53). As Shapiro and Kirksey $(2017,488)$ observe, "the epistemological affordances of sensors risk reinforcing the dominance of science in society and promoting the modernist dream of the imminent calculability and knowability of the material world." And here lies the problem: not even the strongest sensor with the highest-resolution open-source real-time data will be enough to magically manifest environmental justice, especially if that injustice is built on a firm foundation of inequality and oppression. No amount of public participation, however "data rich," will overturn toxic decisions if the participants do not 
"count" (Davies 2019). Put differently, the agency of citizen science - with its offer of a low-fi technological fix - comes into conflict with the structure of environmental injustice - with its entrenched political inequalities. Data, in other words, will only ever be part of the struggle.

Though citizen science may not be the panacea it is sometimes cracked up to be, it nevertheless opens up important debates about the creation of toxic truths. It pulls in fresh perspectives on pollution, enlivens new narratives about injustice, and questions the salience of normative expertise. The authors in this last section of Toxic Truths offer distinct case studies that critically unravel questions about the fundamental nature of citizen science itself. For example, Elizabeth Hoover asks what happens to the notion of citizen science if the very idea of citizenship is contested. By exploring how citizen science and environmental injustice have interacted with an indigenous Mohawk community that spans the US-Canadian border, Hoover shines light on the fact that, for many communities, "citizenship" is not a simple category, especially in settler colonial contexts. João Porto de Albuquerque and André Albino de Almeida also unsettle the lopsided relationship between experts and citizens, and ask if pedagogical perspectives might help produce counter-hegemonic understandings of pollution. Building on this, Anneleen Kenis examines the political work that is needed to translate techno-scientific "fact" into a political reality, by exploring how air pollution data from citizen science programs in Belgium and the UK have produced differing political ecologies. In the last chapter of Toxic Truths, Nick Shapiro, Nasser Zakariya, and Jody Roberts reflect on the limits of creating citizen science data, when data alone will not be enough to deter toxins or produce political change. By pulling apart the taken-for-granted notions of science and citizenship, expert and citizen, data and narrative, these chapters allow deeper reflection on the place of citizen science within environmental justice campaigns. In a post-truth age where all kinds of expertise are regularly being questioned, expanding citizen science might also mean acknowledging its limitations.

\section{References}

Armiero, M., Andritsos, T., Barca, S., Brás, R., Ruiz Cauyela, S., Dedeoğlu, Ç., Di Pierri, M., Fernandes, L. D. O., Gravagno, F., Greco, L., and Greyl, L. 2019. Toxic bios: Toxic autobiographies - a public environmental humanities project. Environmental Justice, 12(1), 7-11.

Berling, T. V. and Bueger, C. 2017. Expertise in the age of post-factual politics: An outline of reflexive strategies. Geoforum, 84, 332-341. 
Bonney R. 1996. Citizen science: A lab tradition. Living Bird, 15, 7-15.

Bonney, R., Phillips, T. B., Ballard, H. L. and Enck, J. W. 2016. Can citizen science enhance public understanding of science? Public Understanding of Science, 25(1), 2-16.

Breen, J., Dosemagen, S., Warren, J., and Lippincott, M. 2015. Mapping grassroots: Geodata and the structure of community-led open environmental science. ACME: An International E-Journal for Critical Geographies, 14(3).

Brown, A., Franken, P., Bonner, S., Dolezal, N., and Moross, J. 2016. Safecast: Successful citizen-science for radiation measurement and communication after Fukushima. Journal of Radiological Protection, 36(2), S82.

Davies, T. 2019. Slow violence and toxic geographies: "Out of sight" to whom? Environment and Planning C: Politics and Space, 1-19.

Gabrys, J. 2014. Programming environments: Environmentality and citizen sensing in the smart city. Environment and Planning D: Society and Space, 32(1), 30-48.

Irwin, A. 1995. Citizen Science: A Study of People, Expertise, and Sustainable Development. London: Routledge.

Jasanoff, S. and Simmet, H. R. 2017. No funeral bells: Public reason in a "post-truth" age. Social Studies of Science, 47(5), 751-770.

Mah, A. 2017. Environmental justice in the age of Big Data: Challenging toxic blind spots of voice, speed, and expertise. Environmental Sociology, 3(2), 122-133.

Ottinger, G. 2010. Buckets of resistance: Standards and the effectiveness of citizen science. Science, Technology, \& Human Values, 35(2), 244-270.

Persily, N. 2017. The 2016 US election: Can democracy survive the internet? Journal of Democracy, 28(2), 63-76.

Polleri, M. 2019. Conflictual collaboration: Citizen science and the governance of radioactive contamination after the Fukushima nuclear disaster. American Ethnologist, 46(2), $214-226$.

Shapiro, N. and Kirksey, E. 2017. Chemo-ethnography: An introduction. Cultural Anthropology, 32(4), 481-493.

Strasser, B. J., Baudry, J., Mahr, D., Sanchez, G., and Tancoigne, E. 2019. "Citizen science”? Rethinking science and public participation. Science \& Technology Studies, 32(2), 52-76.

The Economist 2017. The world's most valuable resource is no longer oil, but data. The Economist, available at https://www.economist.com/leaders/2017/05/06/theworlds-most-valuable-resource-is-no-longer-oil-but-data (last accessed February 6, 2020).

Topçu S. 2013. Chernobyl empowerment? Exporting "participatory governance" to contaminated territories. In S. Boudia and N. Jas (eds), Toxicants, Health and Regulation since 1945. London: Pickering \& Chatto. 